\title{
Geophysical characterization of derelict coalmine workings and mineshaft detection: a case study from Shrewsbury, United Kingdom
}

\author{
J.K. Pringle ${ }^{1 *}$, I.G. Stimpson ${ }^{1}$, S.M. Toon ${ }^{1}$, S. Caunt ${ }^{2}$, V.S. Lane ${ }^{1}$, \\ C.R. Husband ${ }^{1}$, G.M. Jones ${ }^{1}$, N.J. Cassidy ${ }^{1}$ and P. Styles ${ }^{1}$ \\ ${ }^{1}$ Environmental Physical Sciences and Applied Mathematics (EPSAM) Research Institute, School of Physical Sciences \& Geography, \\ Keele University, Keele, Staffordshire, ST5 5BG, UK \\ ${ }^{2}$ The Coal Authority, 200, Lichfield Lane, Berry Hill, Mansfield, Nottinghamshire, NG18 4RG, UK
}

Received July 2007, revision accepted March 2008

\begin{abstract}
A study site of derelict coalmine workings near Shrewsbury, United Kingdom was the focus for multi-phase, near-surface geophysical investigations. Investigation objectives were: 1) site characterization for remaining relict infrastructure foundations, 2) locate an abandoned coalmine shaft, 3) determine if the shaft was open, filled or partially filled and 4) determine if the shaft was capped (and if possible characterize the capping material).

Phase one included a desktop study and 3D microgravity modelling of the relict coalmine shaft thought to be on site. In phase two, electrical and electromagnetic surveys to determine site resistivity and conductivity were acquired together with fluxgate gradiometry and an initial microgravity survey. Phase three targeted the phase two geophysical anomalies and acquired high-resolution self potential and ground penetrating radar datasets. The phased-survey approach minimised site activity and survey costs.

Geophysical results were compared and interpreted to characterize the site, the microgravity models were used to validate interpretations. Relict buildings, railway track remains with associated gravel and a partially filled coalmine shaft were located. Microgravity proved optimal to locate the mineshaft with radar profiles showing 'side-swipe' effects from the mineshaft that did not directly underlie survey lines.

Geophysical interpretations were then verified with subsequent geotechnical intrusive investigations. Comparisons of historical map records with intrusive geotechnical site investigations show care must be taken using map data alone, as the latter mineshaft locations was found to be inaccurate.
\end{abstract}

\section{INTRODUCTION}

The successful detection of near-surface voids and mineshafts using geophysical techniques has been well demonstrated (see Maxwell 1976; McCann et al. 1987; Styles et al. 2005; Branston and Styles 2006). These methods, in comparison to geotechnical methods, can offer a relatively inexpensive and rapidly deployable solution that can provide a more detailed site characterization before intrusive investigations of targeted geophysical anomalies (using conventional boreholes and trial-pits) are undertaken.

Bulk ground resistivity and conductivity surveys can be used to actively measure the electrical properties of a volume of material below a sample position (see Reynolds 1997) and have been

*j.k.pringle@esci.keele.ac.uk shown to be very effective at detecting cleared building foundations and, indeed, mineshafts in some cases (McCann et al. 1987). Resistivity measurements determined using direct electrical methods are typically less sensitive to the cultural 'noise' produced from surface objects such as metal fences and oil tanks than conductivity measurements obtained using electromagnetic (EM) methods. Magnetic surveys are sensitive to near-surface ferrous materials, which can be associated with building foundations, railway tracks or other near-surface metal. Magnetometry has also been shown to be successful at detecting mineshafts because scrap metal was often thrown into the shaft during filling in at abandonment (McCann et al. 1987). Fluxgate gradiometry surveys measure the local magnetic field gradient over a sample position between two vertically orientated fluxgate magnetometers. These results are, therefore, more sensitive to near-surface survey site 

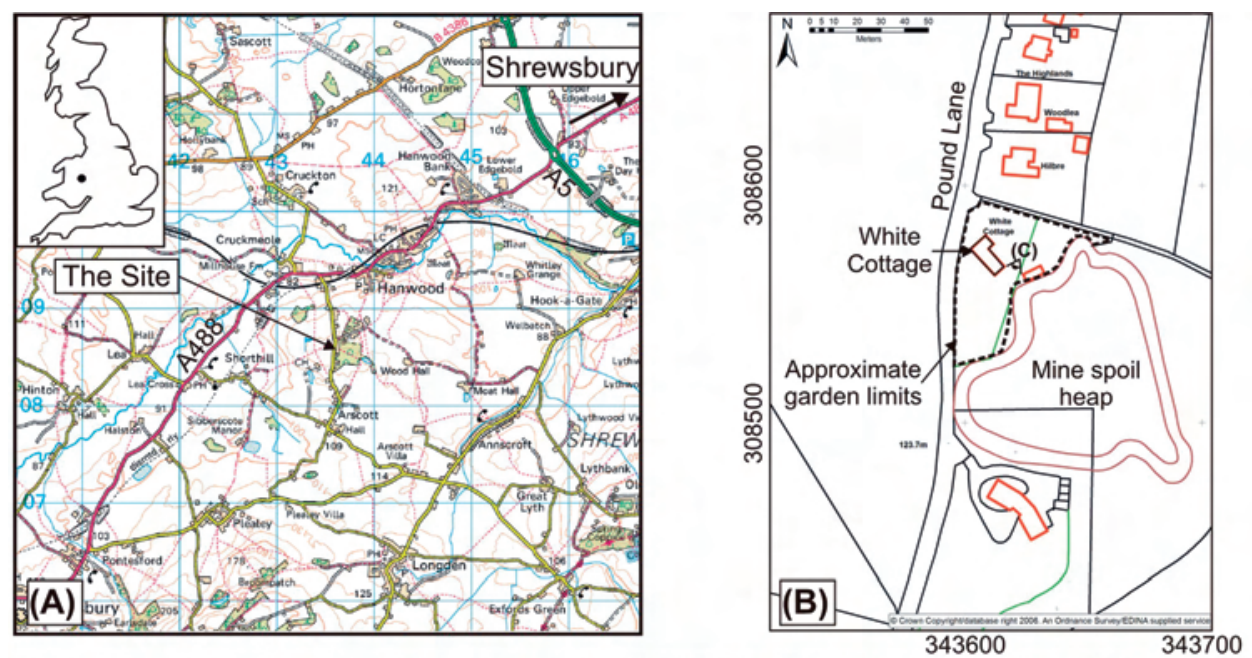

FIGURE 1

Annotated a) location map with b) site map and c) site photomosaic. b) Shows location and direction where c) photomosaic was taken. Images supplied by Ordnance Survey/EDINA service. (C) Crown Copyright Database 2007.

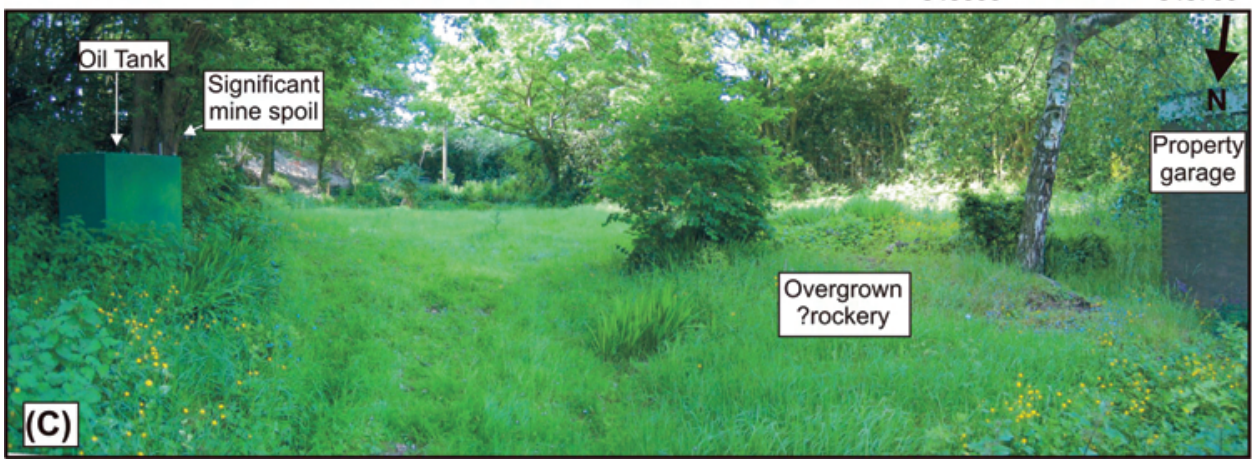

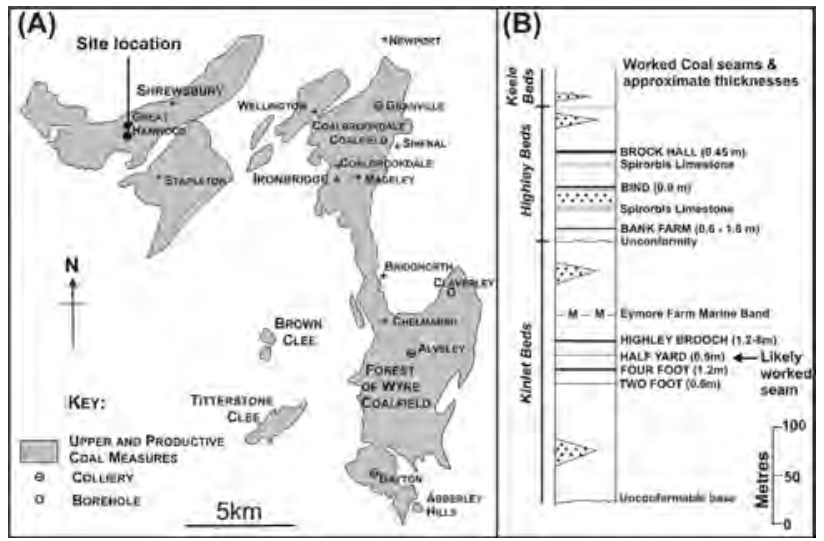

FIGURE 2

a) Map of Shrewsbury coalfield and b) Local Carboniferous Coal Measures stratigraphy. Site location and the likely worked seam are marked. Adapted from Hull (1873).

material but can also suffer from surface cultural 'noise'.

Although relatively slow to acquire, micro-gravimetric surveys have been shown by many authors to produce high-resolution maps of near-surface voids or cavities (Fajklewicz 1976; Butler 1984; Emsley and Bishop 1997; Styles et al. 2005; Branston and Styles 2006). Two- (and three-) dimensional microgravity profiles can also be modelled and inverted; there- fore, allowing the size and depth of voids below ground level (bgl) to be estimated.

The self potential (SP) method measures surface electrical current differences from their associated voltage (potential) signals and have been recently used to locate subsurface voids (Quarto and Schiavone 1996; Jardani et al. 2006). Subsurface voids have been found to create both positive and negative SP anomalies; the polarity of the SP anomaly is believed to be due to the composition of cavity fill. The exact mechanisms responsible for creating SP anomalies over cavities are subject to debate (Green 2000; Lange 2000), but the general consensus is that the SP anomalies can be attributed to the preferential percolation of water within or around the cavity. SP has been successfully shown by other authors to detect mineshafts (BGS Report 2004; Wilkinson et al. 2005).

The ground-penetrating radar (GPR) method is commonly used in geotechnical engineering, for example, to determine soil and rock stratigraphy (Davis and Annan 1989), detect pavement voids (Nichol and Reynolds 2001) and detecting cleared building foundations, cellars and utility services (Grandjean et al. 2000). This is due to both the comparatively high-resolution data recorded from higher frequency (225 MHz) near-surface GPR systems and their relative ease of use. GPR has also been used successfully for mineshaft detection (Kulessa et al. 2004).

This paper presents multi-disciplinary research over derelict 

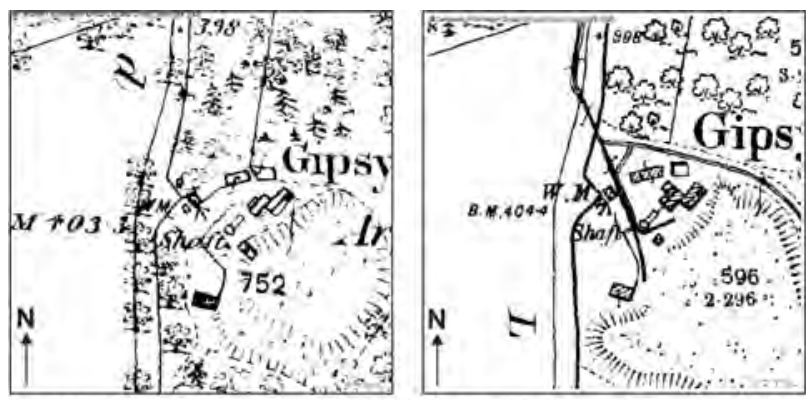

(A) 1:2,500 County Series (1854-190

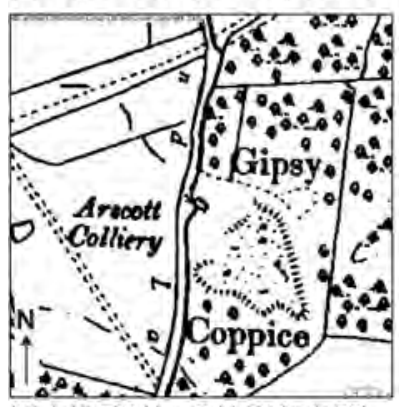

(C) $1: 10,560$ Nat. Grid (1948-1977)
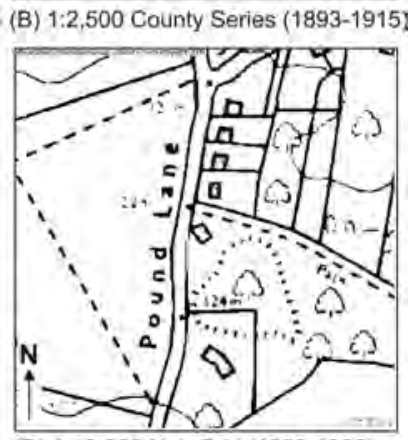

(D) 1:10,000 Nat. Grid (1969-1996)

\section{FIGURE 3}

Historical site records a) 1882, b) 1902, c) 1954 and d) 1976, showing the differing positions of the mineshaft, spoil heap, onsite buildings and a rail system. (C) Crown Copyright and Land Information Group Ltd 2007, all rights reserved. coal mine workings located close to the village of Hanwood, near Shrewsbury, Shropshire, UK (Fig. 1). Geological records indicate that Devonian glacial-till drift deposits overlie Keele Formation sandstones, which themselves overlie Carboniferous Upper Coal Measures of the Hanwood Coalfield (Fig. 2a), part of the larger Shrewsbury Coalfield (Hull 1873). The three main seams worked in the area were the 'Yard', ' $1 \frac{1}{2}$ Yard' and 'Best Coal' seams (Fig 2b), with records (Brown 1976) which showed that the site was locally worked by the Arscott Colliery. All commercial mining ceased in the area in the 1940s (Trueman 1954). Today, the site lies within the garden of a private residence (Fig. 1c) and has been landscaped with clay-rich topsoil, although there is estimated to be $(8 \mathrm{~m}+)$ thickness of mine spoil still present below ground level. An approximately $2 \mathrm{~m}$ high, irregularly-shaped raised area to the East was presumably former mine spoil, as shown on historical records (Fig. 3).

Geophysical results of bulk ground resistivity, micro-gravity, SP, magnetic and GPR geophysical surveys conducted within the site grounds in 2006 are detailed together with the subsequent 2007 documented intrusive investigation of the targeted geophysical anomalies. The objectives for the investigation were to: 1) characterize the site for remaining relict coalmine infrastructure foundations, 2) locate the abandoned coalmine shaft, 3) determine if the shaft was open, filled or partially filled and 4) determine if the shaft was capped (and if possible characterize the capping material).
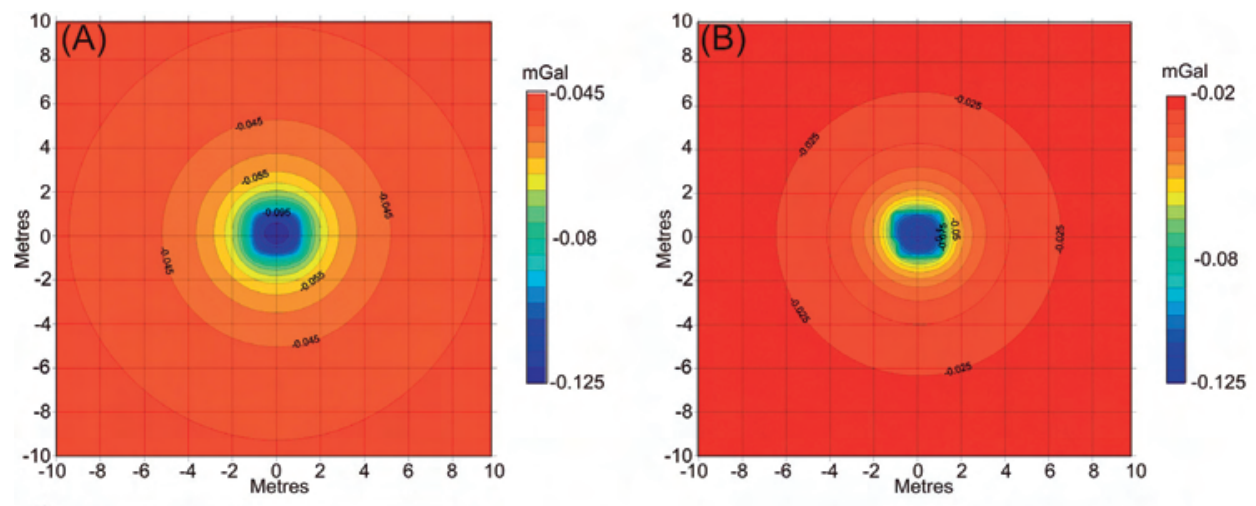

FIGURE 4

3D MATLAB ${ }^{\mathrm{TM}}$ microgravity models of an a) open, b) partial and c) filled mineshaft with d) 2D profile comparisons. The modelled mineshaft is based on historical records and is $2.5 \mathrm{~m}$ in diameter and $110 \mathrm{~m}$ deep.
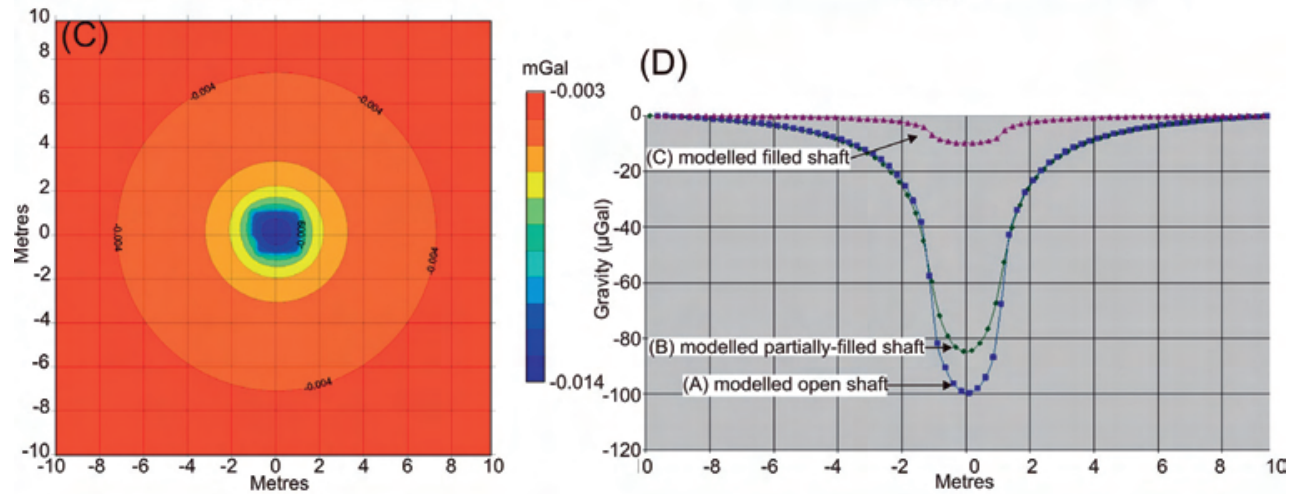


\section{METHODOLOGY}

A three-phase survey approach was used during this case study. Phase one entailed a 'desk-study' investigating the historical records to assess both the likely position of relict mine infrastructures and the possible size of the coalmine shaft. Phase two entailed acquiring geophysical datasets over the part of the survey area identified by the phase one desk study, whilst phase three collected high-resolution data over any anomalous geophysical areas identified during phase two. Bulk ground resistivity, conductivity, magnetic fluxgate gradiometry, microgravity, Self Potential and Ground Penetrating Radar techniques were all employed.

\section{PHASE I DESK STUDY}

The desktop study initially sourced historical records of the site, archive maps (Fig. 3) showing various onsite mine buildings and related infrastructure within the last 150 years. The buildings, railway and other features, however, have differing positions on the various map series, partly due to different map projections, and therefore cannot be relied upon to indicate the true location of a feature. This is not uncommon, as transference between successive versions of mine abandonment plans often leads to misplotting, sometimes duplication and even omission of data. The records do, however, show the site was locally worked by the Arscott Colliery.

A 1930 Coal Mine Abandonment Plan (7227) held by The Coal Authority also showed that a vertical access mineshaft (No. 3: 843308-001), was present onsite. Specific information about the shaft was not available, although the plan does show that the $1 / 2$ Yard $(0.5 \mathrm{~m})$ coal seam was located $110 \mathrm{~m}$ (120 yards) below ground level; this was the seam presumably mined at the time of abandonment. Records from the nearby Hanwood Mine (Brown 1976) suggest that the shaft may be approximately $110 \mathrm{~m}$ deep and $2.5 \mathrm{~m}$ in diameter. It was not known whether the shaft had been filled and/or capped and if so, what material was used. Prior to 1945 , shafts were generally filled with unregulated materials and caps were of a poor standard. The exact shaft location cannot be determined from historical maps alone; although several of these suggest that it lies approximately $10 \mathrm{~m}$ to the southeast of a now demolished building (the footprint of which lies within the present-day property). A $\sim 50 \mathrm{~m}$ by $\sim 20 \mathrm{~m}$ irregularly-shaped area to the south of the present house was therefore decided upon for the initial acquisition of the geophysical data.

3D microgravity modelling of a $2.5 \mathrm{~m}$ diameter, $110 \mathrm{~m}$ deep mineshaft was also undertaken using MATLAB ${ }^{\mathrm{TM}}$ software. Both the likely horizontal and vertical microgravity gradient responses were modelled to assess the likely anomaly size and extent that may be produced from an open, partially filled and completely filled mineshaft (Fig. 4). The modelled likely anomalies for these variations would be approximately $100 \mu \mathrm{Gal}$, $80 \mu \mathrm{Gal}$ and $10 \mu \mathrm{Gal}$ respectively, compared to background values (see Fig. 4d).

\section{PHASES II AND III GEOPHYSICAL SURVEYING AND DATA PROCESSING}

Following the initial site inspection and topographic survey using Leica 1200 total station equipment, a northeast-southwest orientated, $1 \mathrm{~m}$-spaced, survey grid was created on the site, located to the south and east of the present-day building (see Fig. 5). The initial grid provided the framework over which the phase II bulk ground resistivity, conductivity, SP and magnetics geophysical techniques could be deployed. Each of these techniques took $\sim 1$ day each, with a two-man field team. These data were acquired at $0.5 \mathrm{~m}$-spaced sampling positions on each survey line in a south to north, one-way pattern. All geophysical data sampling positions were also accurately topographically surveyed using a Leica 1200 System total station theodolite.

For the bulk ground resistivity survey, a RM4 Geoscan resistance meter, mounted on a custom-built, twin-probe array on a mobile frame that featured two $0.1 \mathrm{~m}$-long steel probes set $0.5 \mathrm{~m}$ apart, was used. Reference probes were placed $0.75 \mathrm{~m}$ apart and $0.1 \mathrm{~m}$ into the soil, positioned $20 \mathrm{~m}$ from the survey grid following standard methodologies (Milsom 2001). For the conductivity survey, a Geonics EM38B ${ }^{\mathrm{TM}}$ instrument was carefully zeroed over a conductively quiet area of the site for site calibration. In-phase and quadrature readings were obtained for both vertical (VMD) and horizontal (HMD) component orientations. Typical maximum penetration depths using this device in VMD and HMD mode is $\sim 1.5 \mathrm{~m}$ and $\sim 0.75 \mathrm{~m}$ below ground level, respectively. VMD and HMD conductivity surveys were separately acquired to avoid any potential interference from the different EM fields. For the magnetic survey, a Geoscan FM18 ${ }^{\mathrm{TM}}$ fluxgate gradiometer was carefully zeroed over a magnetically quiet area of the site to remove any potential reading differences that may result from positional variations in instrument orientation relative to magnetic north when acquiring the data (see Reynolds 1997). Magnetic data were then acquired on a south to north, one-way pattern. SP Lead-Chloride based, non-polarizing probe electrodes were used to collect the SP surveys with a reference probe being placed $5 \mathrm{~m}$ outside the grid, whilst the mobile probe was placed $\sim 5 \mathrm{~cm}$ into the ground at each sampling position.

For each of the geophysical datasets obtained, sample position recorded readings were initially transferred to digital spreadsheets and converted to $\mathrm{x}, \mathrm{y}$, value formats. A median filter (using a block size of $1 \mathrm{~m} \times 1 \mathrm{~m}$ ) was applied, before a minimum-curvature gridding surface algorithm (using a block size of $0.5 \mathrm{~m} \times$ $0.5 \mathrm{~m}$ ) was created. Any linear site trends were then removed, before both full site and anomaly subset areas were gridded and contoured as $\mathrm{x}, \mathrm{y}$, value data.

Phase III gravity data were acquired using a Scintrex CG5 ${ }^{\mathrm{TM}}$ gravimeter on each $2 \mathrm{~m}$-spaced sample position using three, 45 -second sampling periods for data quality control. A base station reference was collected at the beginning and end of each day and at approximately 1 hour intervals. Two sets of three 45 -second data periods were acquired at each base station measurement and the relative instrument elevations determined from the total 

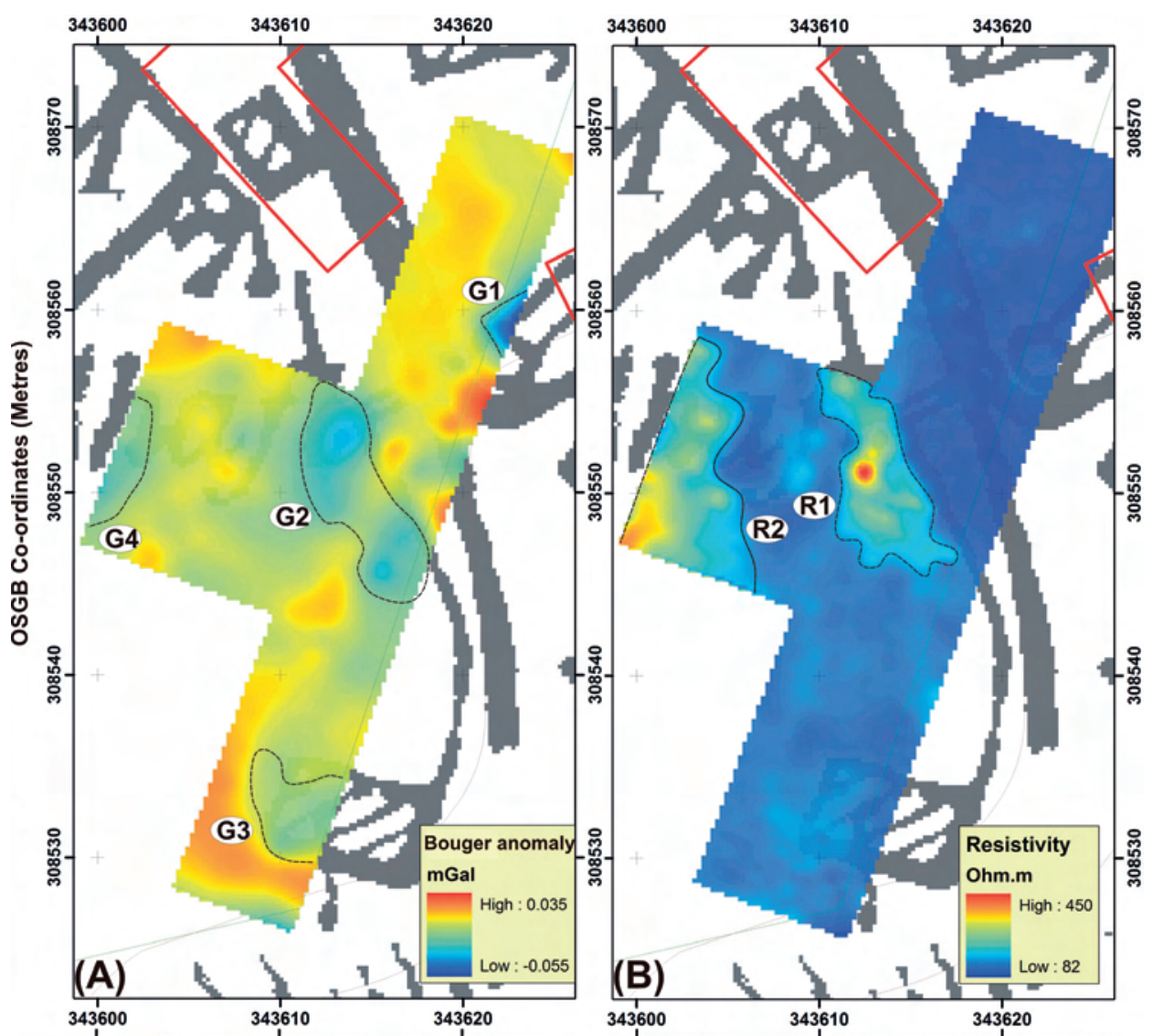

FIGURE 5

Plan (or map) view plots of processed: a) micro-gravity, b) bulk ground resistivity, c) Fluxgate gradiometry and d) SP data collected at the survey site. Interpreted and numbered anomalies are marked (see text). The property's structure is shown in red in the top-left part of the figure. Background map is from the 1902 Ordnance Survey (Fig. 3b).
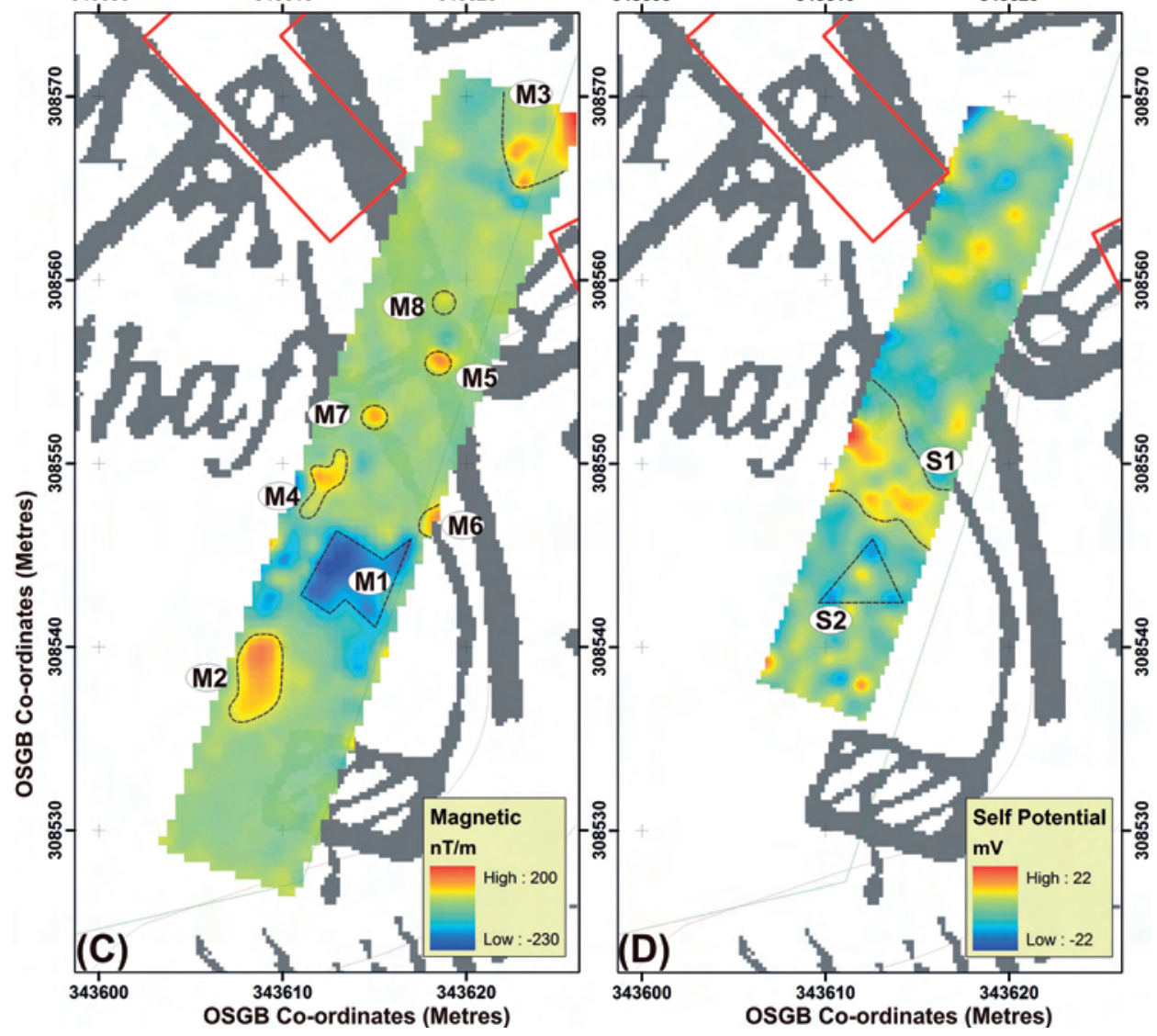

(C) 2008 European Association of Geoscientists \& Engineers, Near Surface Geophysics, 2008, 6, 185-194 

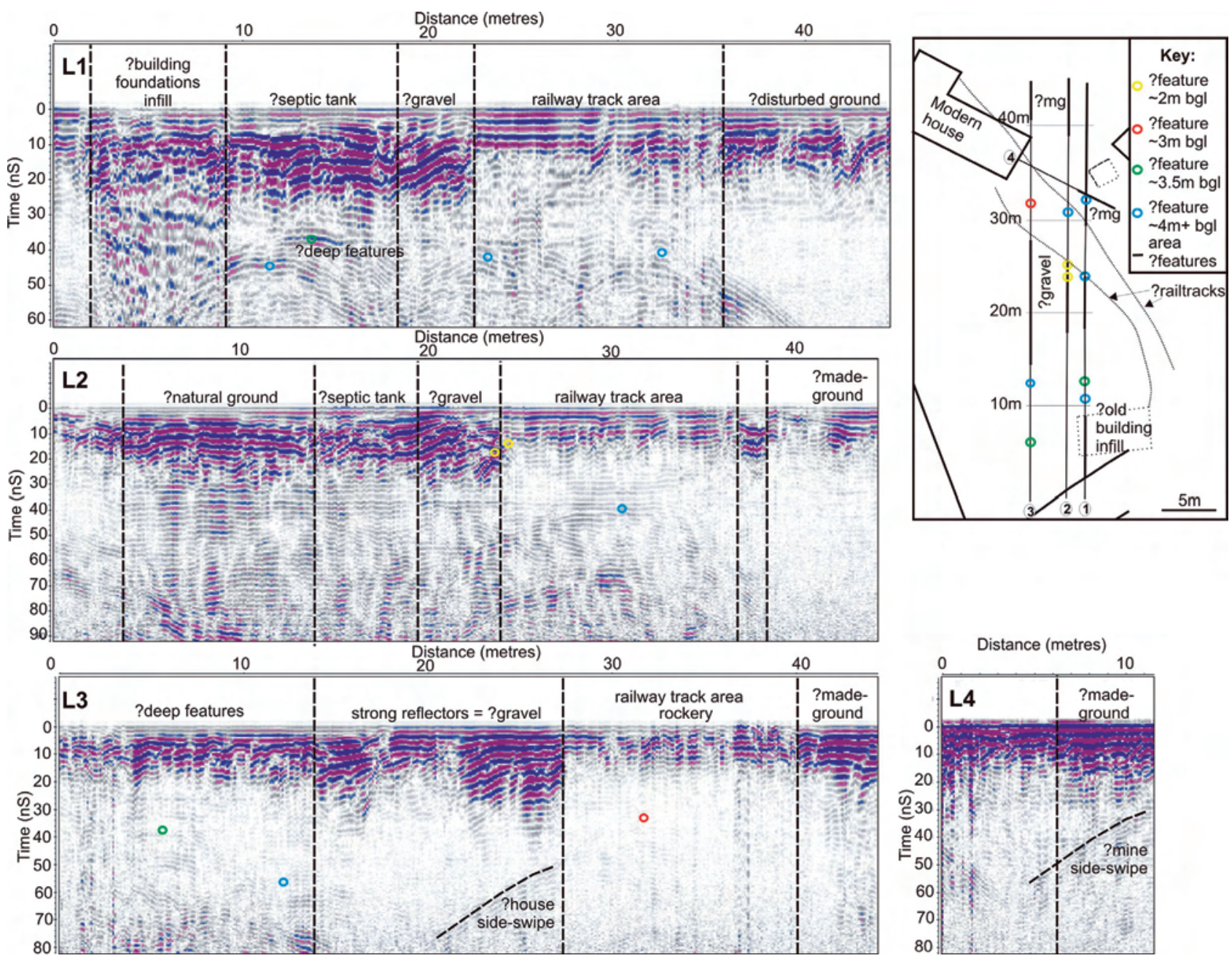

FIGURE 6

2D GPR profiles L1-4 (location on map inset) with interpreted site features and anomalies highlighted. Note the 'side-swipe' feature evident in L4 was probably related to the mine-shaft.

station measurements. In total, 124 gravity readings were made (with a 0.0012 Standard Deviation or SD) with 57 re-observations and 31 base station observations (with a 0.0019 SD). Data were reduced to Bouguer Anomalies, using an initial site ground density of $2.2 \mathrm{Mg} \mathrm{m}^{-3}$, based on the typical subsurface conditions anticipated at the site. Elevation corrections were obtained from the accurately surveyed total station positions (with an average positional error of $0.5 \mathrm{~cm}$ ). Ideally, the adjacent $\sim 2 \mathrm{~m}$-high, mine spoil heap should have also been surveyed, as this extra mass could have interfered with micro-gravity results, but it could not be accessed due to the dense, deciduous woods and vegetation cover. The CG5 was also able to correct for the majority of temporal variations using in-built software, whilst any residual temporal effects due to instrument drift and earth tides were removed using the base station values. The instrument raw files were edited and reduced using in-house software. The base station residuals were always less than $5 \mu \mathrm{Gal}$. A regional gravity gradi- ent across the study site was also removed using in-house processing procedures and software.

Phase III GPR data were also acquired following initial tests with PulseEKKO ${ }^{\text {TM }} 1000225 \mathrm{MHz}$ and $450 \mathrm{MHz}$ antennae to determine the optimum frequency. $225 \mathrm{MHz}$ antennae were subsequently used to acquire the $2 \mathrm{D}$, fixed-offset $(0.25 \mathrm{~m})$ bistatic, co-planar, broadside profiles over the survey lines (Fig. 6) with $5 \mathrm{~cm}$ trace spacing and an $80 \mathrm{~ns}$ time window. Thirty-two repeat pulse stacks were used on all profiles to improve the signal-to-noise ratio (see Milsom 2001). GPR PulseEKKO ${ }^{\mathrm{TM}}$ raw data files were imported into REFLEX-WTM processing software. For each $2 \mathrm{D}$ profile, the first break arrival was picked and flattened to $0 \mathrm{~ns}$. A time-cut was applied to remove blank data at the base of each profile before standard 'dewow' and DC_shift' filters were applied. A manual gain function was also applied to boost deeper reflection event amplitudes. A site average velocity of $0.11 \mathrm{~m} / \mathrm{ns}$, obtained by a 
common-mid-point (CMP) profile, was used to convert the 2D profiles from time (nanoseconds) to depth (metres). The resulting profiles were then exported as images (Fig. 6).

\section{RESULTS AND INTERPRETATION}

The interpreted microgravity results identified four anomaly lows with respect to background values (G1-G4 on Fig. 5a). Comparisons of these anomalies with the modelled profiles (Fig. 4) indicated that anomaly G1 was the most likely position for a mineshaft, due to its size and low anomaly amplitude (approximately $-55 \mu \mathrm{Gal}$ with respect to background values). The G1 low anomaly value was probably accentuated by the digital surface gridding algorithm, due to its edge position. The mineshaft was theorized to be partially filled (Fig. 4). Gravity anomaly low G2 (approximately $-20 \mu \mathrm{Gal}$ with respect to background values) was bounded to the north by an old railway track shown on the historical records and may, therefore, be attributed to different ground material from the surrounding area, perhaps related to the presence of the railway. Gravity anomaly G3 (approximately $-10 \mu \mathrm{Gal}$ with respect to background values) correlated with a now-demolished building shown on the 1903 historical map and was likely to be related to the foundations or demolished remains of this feature. The origin of Gravity anomaly G4 (approximately $-10 \mu \mathrm{Gal}$ with respect to background values) was unknown but was of similar amplitude as anomaly G2 and may therefore be due to the presence of similar demolition material.

The resistivity results showed a high (400 $\Omega \mathrm{m}$ ) anomaly (R1 on Fig. 5b), with a SE-NW orientation. A high resistivity anomaly would be expected over an open shaft (as air is highly resistive) but the anomaly was relatively dispersed and showed a preferred orientation that was inconsistent with the presence of a vertical shaft. A comparison of the R1 anomaly to the 1903 maps shows it was bordered to the north by a railway track. It was also noted that during the resistivity acquisition the electrodes penetrated a coarse 'gravel' layer in this area that may be railway ballast (or similar, higher-resistivity material), which may be responsible for this anomaly. A resistivity $(200 \Omega \mathrm{m})$ anomaly (R2 on Fig. 5b) was also observed in the western part of the study area. This was also interpreted to be a similar high-resistivity material, probably a gravel/ballast layer.

In contrast to the resistivity, the conductivity results were generally poor. This could be due to the limited penetration depth of the instrument used. Two strong high isolated anomalies ( $25 \mathrm{mS} / \mathrm{m}$ with respect to background values) that could be correlated to an onsite household oil tank and an observed, protruding metal spike in the ground that was most probably masking out the other site features. Attempts to filter these values out were unsuccessful; these data are therefore not shown for brevity.

The fluxgate gradiometry results (Fig. 5c) showed a low magnetic anomaly (-80nT compared to background values) M1 that was rectangular in shape. This anomaly was interpreted as being man-made due to its highly regular shape but could not be correlated to any features in the historical records. This was there- fore assumed to be a modern feature, possibly a septic tank. A magnetic high, anomaly M2 (200 nT) was not explained, whilst a similar anomaly (150 nT) to the north of the grid (M3) was interpreted as ferrous-rich, near-surface ground fill. Anomaly M4 was interpreted as being associated with the septic tank (possibly a pipe?) whilst the anomalies M5-8 correlated to the railway tracks shown in the 1903 map. These were interpreted as relict railway anchor pins that were used to tie the sleepers to the ground and left in place after the track was removed.

The SP results (Fig. 5d) showed a clear band of large, high readings (anomaly S1 - 10 mVolts compared to background values), which was also bounded by the old railway track to the north. This was therefore interpreted to be associated with the gravel/ballast area as it correlated with the resistively high

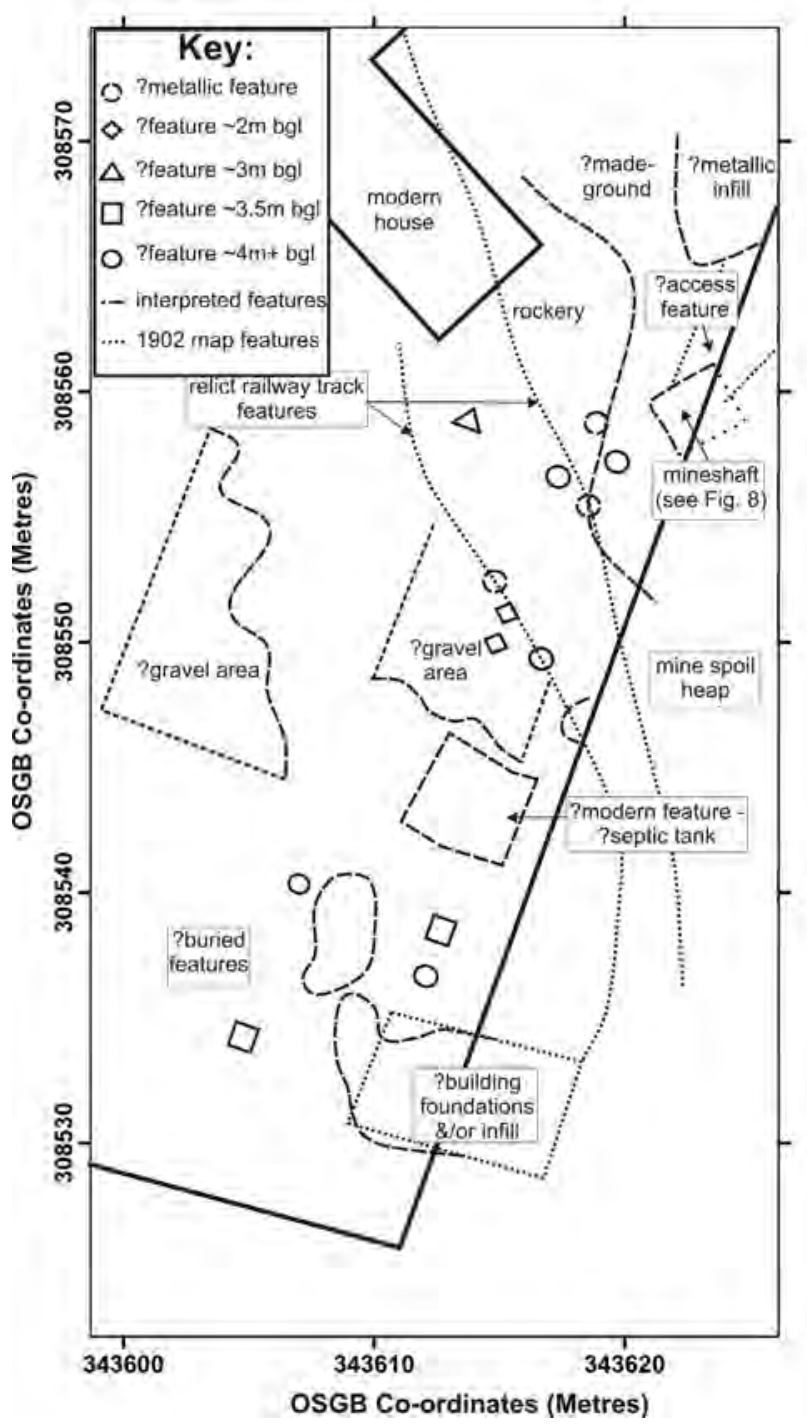

FIGURE 7

Summary plot showing the positions of interpreted geophysical anomalies. 

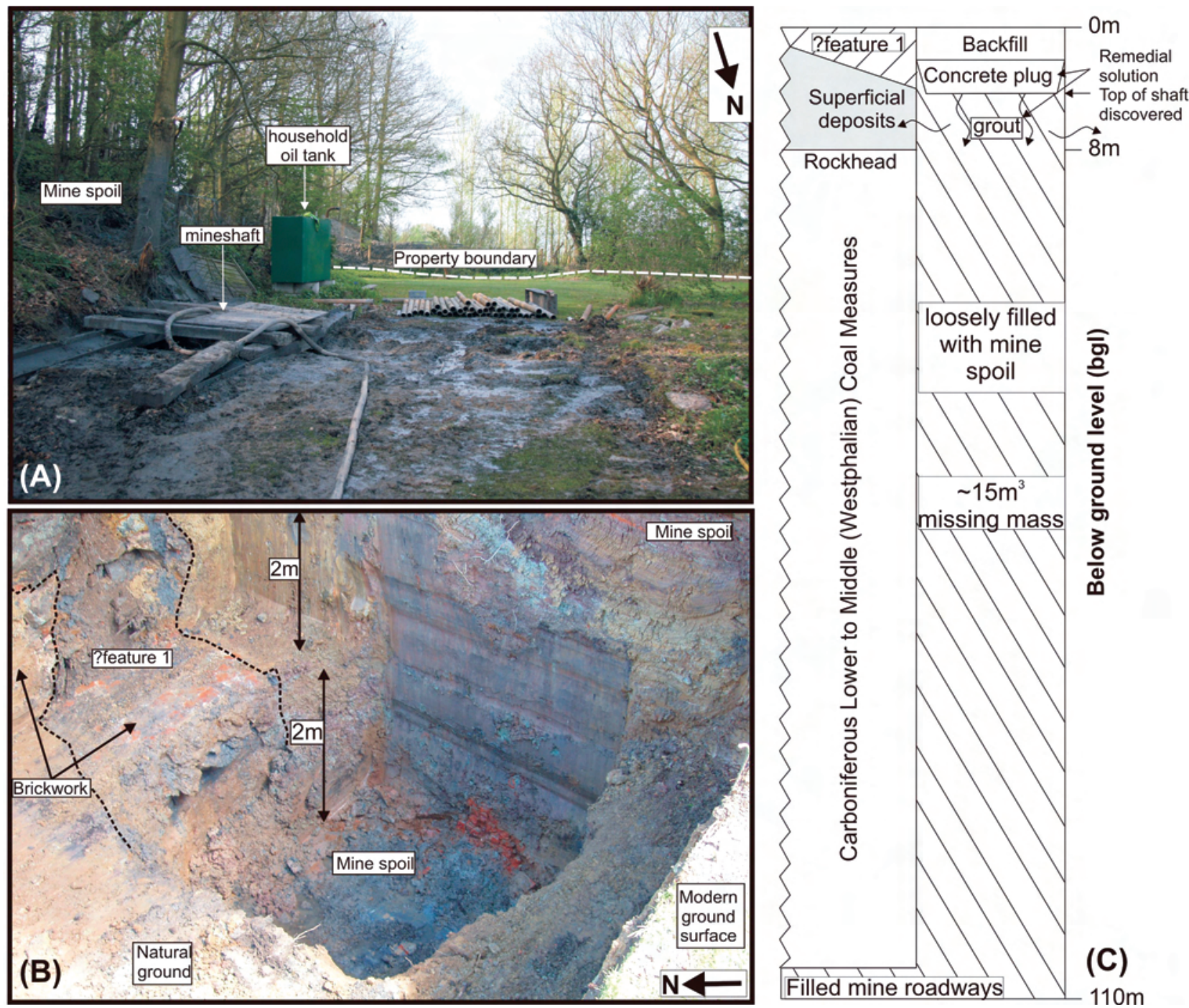

FIGURE 8

Site investigation: a) discovered mineshaft, b) partial excavation, c) schematic of the shaft and remediation solution. Note feature 1 in b) shows a loose infill area that may be associated with location of shaft equipment (e.g. winch foundations, etc).

anomaly R1. SP anomaly S2, however, seemed to be comprised of three low areas in a triangular pattern that correlated with the magnetic (M1) anomaly and was, therefore, interpreted as being associated with this modern feature.

The $225 \mathrm{MHz}$ 2D GPR profiles, L1-4, have been interpreted and sub-divided into different areas, based on their GPR characteristics (Fig. 6). These differences could be correlated across the profiles, shown schematically in the map-view interpretation of Fig. 6.

On the L1 2D profile, a weak, chaotic reflective area (located between $2-9 \mathrm{~m}$ along the profile) could be correlated with the 1902 building plan and was interpreted as either building foundations or infill. Several deep, half-parabola point-source reflectors (at 12 and $14 \mathrm{~m}$ ) could be correlated with the magnetic low (M1) anomaly and was thus interpreted as the modern, possibly septic tank, feature. Strong reflectors were evident $(18-22 \mathrm{~m})$ in the region where gravel/ballast has been interpreted from the resistivity surveys, whilst planar reflections were encountered where railway tracks were located on the 1902 map (22 - 36 m). Lastly, an area of chaotic reflectors $(36-43 \mathrm{~m})$ was interpreted to be disturbed ground.

On the L2 2D profile, an area $(4-14 \mathrm{~m})$ showing strong planar reflectors was interpreted as natural ground before being succeeded by an area $(14-19 \mathrm{~m})$ that had deep parabolas present and was similar to features observed on the L1 2D profile. These deep parabolas were therefore interpreted as being the septic tank. Northward dipping reflectors were then observed (19$24 \mathrm{~m}$ ) that were interpreted to be the gravel area, before more 
planar reflectors were observed $(24-36 \mathrm{~m})$ that were interpreted as the railway track area. The northerly part of the profile was then composed of chaotic reflectors that were interpreted as being made ground.

On the L3 2D profile, an area $(0-13 \mathrm{~m})$ showed strong, planar reflectors and was interpreted as natural ground with several deep, parabolic, point-source reflectors (at 15 and $12 \mathrm{~m}$ ) being located at the start of the profile that may indicate isolated, buried features. The dipping reflectors present between $13-27 \mathrm{~m}$ were interpreted as being associated with the gravel/ballast layer, together with 'side-swipe' effects from the modern house foundations (this can be seen near the bottom of the profile). Poor data quality complicates the data interpretation in the old railway track area (now a rockery $-27-40 \mathrm{~m}$ ), before interpreted made ground was encountered at the end of the profile.

On the short L4 2D profile, chaotic reflectors were initially observed (probably due to acquiring data over the rockery area) before an area $(6-11 \mathrm{~m})$ of chaotic reflectors was observed. This latter area was very close to the presumed mine-shaft location, and had a strong amplitude, deep, westward dipping reflector/quasiparabolic reflection near the base of the profile. This feature was most probably related to a sub-surface object that did not lie directly underneath the profile, as there were no likely aboveground structures in this area that could be the other cause. This parabola was located close to a gravity anomaly (G1) that was suggested to be the mineshaft and thus added further geophysical evidence for the mineshaft to be located at this position.

\section{GEOTECHNICAL INTRUSIVE INVESTIGATIONS AND SUBSEQUENT REMEDIATION}

Subsequent intrusive site investigations undertaken by geotechnical engineers found the mineshaft to be centered approximately $8 \mathrm{~m}$ south-east of the property garage (Fig. 8a). The mineshaft diameter was also confirmed to be $2.5 \mathrm{~m}$, based upon probes drilled around this position. The shaft was filled with superficial deposits of rubble, and with no open entry into the actual mine workings. It was calculated that there was only $15 \mathrm{~m}^{3}$ of material missing from the shaft, as 30 tonnes of grout were needed to fill the small voids in the mineshaft fill.

During excavations, supporting wall brickwork was found to the north of the shaft (Fig. 8b) with quite different fill than the mineshaft, with the floor of this feature having an apparent $20^{\circ}$ dip to the north. It was difficult to interpret the original use of this feature but it could be an access walkway to the shaft entrance or foundations for winding equipment, but these interpretations are speculative. If this feature continues to the north of the shaft, then it could be correlated with the magnetic (M3) anomaly (Fig. 5c).

It is commonly considered best practice to remediate old UK mineshafts by drilling to the rock head, stabilizing the shaft, filling it with concrete and then capping with reinforced concrete from the rock head to the surface. However, it was not possible to do this on this site, due to the thick superficial mixture of mine spoil and soil deposits ( $8 \mathrm{~m}$ thick) overlying the rock head and the proximity of both the spoil mound and site boundary to the shaft. A concrete 'plug' was therefore installed from $0-2 \mathrm{~m}$ below ground level with grouting around this plug to stabilize it (see Fig. 8c). It was also recommended that no development should take place within $5 \mathrm{~m}$ of the mineshaft (Edmondson, pers. comm.).

\section{DISCUSSION}

Of the geophysical surveys trialled, microgravity was deemed the optimal location technique, since although the subsequent intrusive investigations confirmed that the mineshaft was located at the very edge of the survey area, microgravity still identified its location. The 3D microgravity modelling of the coalmine shaft prior to data acquisition was highly useful, as it helped to identify its likely location when interpreting the phase two geophysical results. This approach allowed the detailed phase three geophysical investigations to be undertaken in the geophysically anomalous areas. Modelling also allowed the likely characteristics of the shaft fill to be ascertained, which was important information for the geotechnical engineers before initiating site remediation. The microgravity and GPR survey also delineated the building located at the south of the survey site that was on the 1902 historical map.

The railway track that was shown on the 1902 historical map had a significant effect on the site, although no surface evidence remains. Various magnetic anomalies (M5-8) could be correlated to the track position that are speculated as being potential relict sleeper anchor tie pins or associated metallic remains. The southerly railway track also provided a sub-site border with an interpreted gravel/ballast area located directly to the south that was identified by microgravity (G2), SP (S1) and bulk ground resistivity (R1) techniques.

A magnetic (M1) and SP (S2) low anomaly area was identified that did not correlate with the historical features, but this was interpreted as post-dating the 1902 maps and probably associated with the building phase of the present house. It was also delineated in high resolution by the GPR profiles during the phase three investigations and was interpreted as being related to a septic tank.

Generally, the GPR results provided the high-resolution, stratigraphic information necessary to confirm the other geophysically identified target anomalies, and most importantly, observed 'side-swipe' effects on the L4 profile added weight to the microgravity anomaly G1 being the coalmine shaft. GPR results showed that even if GPR profiles were not directly over targets, they can still be detected. Numerous, relatively deep, parabola point-sources were also identified over the site, which probably indicated relict buried objects associated with the workings.

Due to the confined site access conditions, several of the important geophysical anomalies were located close to survey boundaries and this had a bearing on the processing and interpretation of the geophysical datasets. Despite this apparent limita- 
tion, it has still been possible to identify and locate the key features of the site and provide accurate information for the process of engineering an appropriate remediation strategy.

It should also be noted that in the investigation of former industrial sites, historical map records should be used with caution due to their lack of accuracy. The 1976 map, for example, showed features that had a spatial footprint of over $10 \mathrm{~m}$ different from both other map projections and the true location of the modern site (determined by both GPS and modern maps).

\section{CONCLUSIONS}

For this complex, derelict coalmine site of limited survey extent, the multi-technique geophysical investigations have been found to be very useful for site characterization and it was possible to extract the maximum amount of relevant site information in order to aid the subsequent targeted geotechnical investigations. Using multiple geophysical techniques allowed a three-phased survey approach to be adopted, minimizing site activity, surveying and potential costs. Undertaking 3D microgravity modelling prior to surveying also allowed the most likely geophysical anomalies to be further investigated, which subsequently reduced survey time onsite. Due to the presence of 'side-swipe' effects from the subsurface features, GPR was shown to assist in target detection even when survey lines were not directly coincident with the casual features. The results of this study have shown that despite the apparent complexity of the site, near-surface geophysics can benefit geotechnical engineers in confined, derelict industrial sites by rapidly characterizing the ground conditions and identifying anomalous areas for subsequent intrusive investigations.

\section{ACKNOWLEDGEMENTS}

Colin Barnett is acknowledged for access to the site. We are grateful to Keith Edmondson for geotechnical borehole information and for Figure 8(b). The Keele University geophysical and survey equipment used during this research were obtained from a 2003 UK HEFCE equipment bid. Geomatrix Ltd is acknowledged for the loan of Geonics EM38B ${ }^{\mathrm{TM}}$ equipment for the project. This manuscript benefited from reviews by Reinhard Kirsch, Ugur Yaramanci and an anonymous reviewer.

\section{REFERENCES}

Branston M.W. and Styles P. 2006. Site characterization and assessment using the microgravity technique: A case history. Near Surface Geophysics 4, 377-386.

Brown I.J. 1976. Historical Industrial Scenes: The Mines of Shropshire. Moorland Publishing Company.

British Geology Survey Report over a test mineshaft. 2004. http://www.bgs.ac.uk/programmes/envhaz/etp/clients.html
Butler D.K. 1984. Microgravimetric and gravity gradient techniques for the detection of subsurface cavities. Geophysics 49, 1084-1096.

Davis J.L. and Annan A.P. 1989. Ground-penetrating radar for high-resolution mapping of soil and rock stratigraphy. Geophysical Prospecting 37, 531-551.

Emsley S.J. and Bishop I. 1997. Application of the microgravity technique to cavity location in the investigations for major civil engineering works. In: Modern Geophysics in Engineering Geology (ed. Geological Society Engineering Group), pp. 183-182. Geological Society London.

Fajklewicz Z. 1976. Gravity vertical gradient measurements for the detection of small geologic and anthropogenic forms. Geophysics 41, 1016-1030.

Grandjean G., Gourry J.C. and Bitri A. 2000. Evaluation of GPR techniques for civil-engineering applications: Study on a test site. Journal of Applied Geophysics 45, 141-156.

Green D. J. 2000. Discussion: Geophysical studies at Kartchner Caverns State Park, Arizona. Journal of Caves and Karst Science 62, 27.

Hull E. 1873. The Coal-fields of Great Britain: Their History, Structure and Resources. Watson \& Hazell Publishers, London.

Jardani A., Revil A. and Dupont J.P. 2006. Self-potential tomography applied to the determination of cavities. Geophysical Research Letters 33, 1-4.

Kulessa B., Ruffell A. and Glynn D. 2004. Characterising ground hazards induced by historic salt mining using ground-penetrating radar. In: Geotechnical and Geophysical Site Characterisation (eds. A.V. de Fonseca and P.W. Mayne), pp. 497-504. Millpress, Rotterdam.

Lange A.L. 2000. Reply: Geophysical studies at Kartchner Caverns State Park, Arizona. Journal of Caves and Karst Studies 62, 28-29.

Maxwell G.M. 1976. Old mineshafts and their location by geophysical surveying. Quarterly Journal of Engineering Geology 9, 283-290.

McCann D.M., Jackson P.D. and Culshaw M.G. 1987. The use of geophysical surveying methods in the detection of natural cavities and mineshafts. Quarterly Journal of Engineering Geology 20, 59-73.

Milsom J. 2001. Field Geophysics. Geological Society of London Handbook, Open University Press.

Mining Heritage Centre, The Coal Authority. 1930. Arscott No. 3 Abandonment Plan No. 7227.

Nicol D. and Reynolds J.M. 2001. Ground-penetrating radar survey to detect sub-slab voids beneath the East Promenade at Rhyl. Water and Maritime Engineering 148, 47-56.

Quarto R. and Schiavone D. 1996. Detection of cavities by the selfpotential method. First Break 14, 419-431.

Reynolds J.M. 1997. An Introduction to Applied and Environmental Geophysics. John Wiley \& Sons Ltd.

Styles P., McGrath R., Thomas E. and Cassidy N.J. 2005. The use of microgravity for cavity characterization in karstic terrains. Quarterly Journal of Engineering Geology 38, 155-169.

Trueman A. 1954. The Coalfields of Great Britain. Richard Clay \& Company, Ltd.

Wilkinson P.B., Chambers J.E., Meldrum P.I. and Ogilvy R.D. 2005. A comparison of self-potential tomography with electrical resistivity tomography for the detection of abandoned mineshafts. Journal of Environmental and Engineering Geophysics 10, 381-389. 